\title{
Diagnostic utility of median nerve CSA to ulnar nerve CSA ratio in the diagnosis of mild idiopathic carpal tunnel syndrome
}

\author{
Amany Salama El-Bahnasawy', Mohammad K. Senna', Amr El-Sayed Okasha ${ }^{1}$ and Ola Gharbia ${ }^{2 *}$ (D
}

\begin{abstract}
Background: Ultrasonography (US) measurement of median nerve cross-sectional area (m-CSA) at pisiform is increasingly utilized in identification of carpal tunnel syndrome (CTS), but there is still no agreement about the ideal cut-off value to employ. The aim of the study was to explore whether the median CSA to ulnar CSA ratio at the level of pisiform may yield a more accurate diagnosis of CTS. The study included 50 patients with mild idiopathic CTS (ICTS), assessed clinically and by nerve conduction studies, and 50 matched controls. M-CSA, median nerve flattening ratio and swelling ratio (m-SR), palmer bowing, and median CSA to ulnar CSA ratio (m-CAS:U-CSA) were measured for patients and controls. The cutoff values for the US parameters for the diagnosis of ICTS were evaluated.

Results: Compared to the control group, the ICTS group had significantly higher m-CSA $(p<0.001)$, higher m-CSA: u-CSA ratio $(p<0.001)$, higher $\mathrm{m}$-SR $(p=0.012$, and higher palmar bowing $(p<0.001)$. Use of $m$-CSA cutoff value of $11.78 \mathrm{~mm}^{2}$ and CSA:U-CSA ratio cut-off point of 2.97 yielded the greatest sensitivity and specificity for the diagnosis of ICTS.
\end{abstract}

Conclusion: The m-CSA:U-CSA ratio is slightly superior to the m-CSA in the diagnosis of CTS in terms of sensitivity and specificity.

Keywords: Carpal tunnel syndrome, Median nerve cross-sectional area, Median to ulnar ratio

\section{Background}

Carpal tunnel syndrome (CTS) is prevalent in the general adult population, ranging from 2.7 to $5.8 \%$ [1] and accounts for about $90 \%$ of all entrapment neuropathies. Diagnosis of CTS is largely based on clinical findings and electro-diagnostic (EDX) testing [2]. CTS is the most common reason for referral to electro-diagnostic (EDX) testing. However, EDX testing has its own limitations: it does not allow visualization of intrinsic nerve abnormalities (such as bifid nerve, persistent median artery, poor gliding) or structures around the nerve leading to its entrapment (such as accessory muscles, ganglion

\footnotetext{
* Correspondence: dr_ola_gharbia@hotmail.com

2Physical Medicine, Rheumatology and Rehabilitation Department, Faculty of Medicine, Mansoura University, Mansoura, Egypt

Full list of author information is available at the end of the article
}

cysts, tophi, arthritis, and tenosynovitis), and it is painful [3]. Moreover, EDX had a significant proportion of falsenegative and false-positive findings [4]. These issues have prompted the search for other methods to confirm CTS diagnosis.

Ultrasonographic (US) visualization of the median nerve was introduced as a diagnostic alternative that is painless, non-invasive, and inexpensive [5]. In addition, ultrasonography is also able to demonstrate the dynamic movement of the nerve and the surrounding structures that could contribute to the performance of the nerve such as poor gliding and entrapment by the surrounding structures [6]. The most frequently used US method in the identification of CTS is the evaluation of the crosssectional area of the median nerve (m-CSA) at various levels within the carpal tunnel mostly at inlet, mid-
Springer Open

(c) The Author(s). 2020 Open Access This article is licensed under a Creative Commons Attribution 4.0 International License, which permits use, sharing, adaptation, distribution and reproduction in any medium or format, as long as you give appropriate credit to the original author(s) and the source, provide a link to the Creative Commons licence, and indicate if changes were made. The images or other third party material in this article are included in the article's Creative Commons licence, unless indicated otherwise in a credit line to the material. If material is not included in the article's Creative Commons licence and your intended use is not permitted by statutory regulation or exceeds the permitted use, you will need to obtain permission directly from the copyright holder. To view a copy of this licence, visit http://creativecommons.org/licenses/by/4.0/. 
tunnel, and outlet $[7,8]$. Most studies confirmed the reliability of the measurement of m-CSA at pisiform [9, 10]. However, there is still no consensual agreement about the ideal cut-off value to employ.

A large amount of this inconsistency is related to different study designs and measurement methods used, as well as to factors including the age, body mass index (BMI), and gender of the patients [8]. To reduce the discrepancies in the CSA measurements, comparison of the m-CSA to an unaffected nerve that does not pass through the carpal tunnel would be appropriate. In EDX of cases with early and mild CTS, the use of comparative median versus ulnar latencies had improved the diagnosis of CTS with good sensitivity and specificity $[11,12]$. Consistent with this concept, the comparative m-CSA to ulnar CSA ( $\mathrm{u}$ CSA) examination can also be less affected by confounding factors [13]. Therefore, the aim of this study is to explore if the m-CSA to u-CSA ratio at the level of pisiform could yield a more accurate diagnosis of CTS.

\section{Methods}

\section{Subjects}

This case-control study included 50 patients with mild idiopathic CTS (ICTS group) who were collected from the Rheumatology and Rehabilitation Outpatient Clinic, in the period from January 2018 to September 2018. All patients met the following inclusion criteria: (1) age from 18-65 years, (2) diagnosed clinically with CTS according to the criteria of The American Academy of Neurology practice parameters [14] and confirmed by EDX (prolonged median nerve distal motor latencies > $4.4 \mathrm{~ms}$ or prolonged median nerve distal sensory latencies $>3.5 \mathrm{~ms}$ ). Clinical diagnosis of CTS was based on the presence of at least one of the following symptoms: (i) numbness, tingling, or paresthesia in the median nerve distribution; (ii) symptoms are precipitated by repetitive hand activities and relieved by resting and shaking the hand; and (iii) nocturnal awakening by these sensory manifestations. The clinical diagnosis of CTS was supported by the presence of positive Tinel's sign and/or Phalen's sign. The study included also 50 matched volunteers with no current or previous history of CTS. Prior to the inclusion in the study, the aim and procedures were explained in details to the patients and controls, and a written consent was obtained from each participant. The study procedures were approved by the Institutional Research Board.

The exclusion criteria for patients and controls included the presence of diseases with symptoms that mimic CTS, e.g., cervical radiculopathy, proximal entrapment, or polyneuropathy; previous surgical intervention for CTS; history of wrist fracture and recent wrist joint trauma; causes of secondary CTS, e.g., pregnancy, diabetes mellitus, thyroid function disorders, or rheumatic diseases; anatomical abnormalities of the median nerve detected by US examination; and ulnar nerve entrapment at the wrist.

\section{Clinical and laboratory evaluation}

All participants were subjected to thorough medical history taking and clinical examination. The data collected included demographic data such as age and sex, BMI, current clinical symptoms, and co-morbidities. The physical examinations included thorough sensory and motor examination for both ulnar and median nerves. Blood samples were obtained from every participant after overnight fasting to test for fasting blood sugar, T3, T4, SUA (serum uric acid), ESR (erythrocyte sedimentation rate), CRP (C-reactive protein), and RF (rheumatoid factor).

\section{EDX examination}

All EDX testing were performed by an experienced physician, with the skin temperature $>32{ }^{\circ} \mathrm{C}$, using a standardized device (Neurowerk, EMG 2 channels, SIGMA Medizin-Technik, Germany, serial no.: 65258614). The median motor nerve conduction studies were performed. The motor distal latency, peak amplitude, and motor conduction velocity were measured. The median nerve sensory conduction parameters were performed antidromically. The distal peak sensory latency, peak amplitude, and conduction velocity were measured [14].

For motor conduction testing of the ulnar nerve, the active recording electrode was placed over the abductor digiti minimum muscle while the ulnar nerve is stimulated at the wrist, $8 \mathrm{~cm}$ proximal to the active recording electrode. Sensory ulnar nerve conduction was measured anti-dromically, with a recording electrode on the little finger with the distance between the stimulation and recording electrodes of $14 \mathrm{~cm}$ [14]. Motor and sensory distal latencies, peak amplitude, and conduction velocity were measured and compared to normal values to exclude ulnar nerve entrapment and neuropathy.

\section{US examination}

All US examinations were performed by an experienced operator who was blinded to all clinical findings of the patients. US were done with a $7-13 \mathrm{MHz}$ linear array probe with a standardized device (Siemens Acuson P300, Italy). US examinations were performed at the same day of EDX examinations. US examination was done with the wrist placed at the neutral position. The US operator had applied only a slight compression force to avoid the induction of artificial deformation of the examined nerves. The following tests were performed:

1) The m-CSA was measured 3 times at the level of the most protuberant portion of the pisiform bone. 
The average of the three measurements was calculated $[15,16]$.

2) Measurement of the flattening ratio (ratio of the transverse diameter to the anteroposterior diameter of the median nerve) at the level of the hook of hamate [17].

3) Median nerve swelling ratio ( $\mathrm{m}-\mathrm{SR}$ ):m-CSA was also measured $4 \mathrm{~cm}$ proximal to the distal end of radius. The mean of the three measurements is calculated. The m-SR was calculated as m-CSA at the pisiform $/ \mathrm{m}$-CSA $4 \mathrm{~cm}$ proximal to the distal end of the radius [18].

4) Palmar bowing was assessed by the measurement of the length of a vertical line from the flexor retinaculum most-bulging point to a line from the notch of the hamate to the trapezoid tubercle. The mean value of three palmar bowing measurements will be calculated [18].

5) Three measurements of the u-CSA at the same level of median nerve were performed. The mean of the three measurements is calculated. The m-CSA:uCSA ratio was obtained by dividing $\mathrm{m}$-CSA by the u-CSA [18].

\section{Statistical analysis}

All statistical analyses were performed by the use of SPSS v.20. Categorical data were expressed as number and percent. The chi-square test was used to compare variables with categorical data. Variables with continuous data were expressed in mean \pm standard deviation (SD). The Student $t$ test was used for comparison between the two variables containing continuous data. The 95\% confidence interval of the mean difference was calculated. ROC curves were drawn to determine the diagnostic utility of the m-CSA and m-CSA:u-CSA ratio for the identification of patents with CTS. The diagnostic value of the generated cut-off points of the m-CSA and m-CSA:u-CSA ratio was also calculated. The $95 \%$ confidence interval of the diagnostic value of the suggested cut-off points was calculated. Significance was set as the $p$ value $\leq 0.05$.

\section{Results}

Fifty patients with mild ICTS (47 females and 3 males) were enrolled in the study. The duration of the ICTS ranged from 3 to 15 months with an average of $8.5 \pm 4.0$ months. Tinel's test was positive in $70 \%$ of the hands, and Phalen's test was positive in $78 \%$ of the hands in the ICTS group (Table 1).

Most patients $(n=48)$ were right-handed, and 8 had bilateral ICTS while 42 had unilateral ICTS. In patients with bilateral ICTS, the data of the dominant hand was included in the statistical analysis. The study included also 50 healthy volunteers as the control group (45
Table 1 Comparison of the age, sex, BMI, and clinical findings between the ICTS group and the control group

\begin{tabular}{llll}
\hline & ICTS group & Control group & $p$ \\
\hline $\begin{array}{llll}\text { Age (years) } \\
\text { Range }\end{array}$ & $22-60$ & $23-60$ & \\
Mean \pm SD & $40.4 \pm 11.9$ & $41.6 \pm 11.1$ & 0.598 \\
Sex $(n, \%)$ & & & \\
Females & $47(94.0 \%)$ & $45(90.0 \%)$ & 0.461 \\
Males & $3(6.0 \%)$ & $5(10.0 \%)$ & \\
BMI (kg/m $\left.{ }^{2}\right)$ & & & 0.717 \\
Range & $20.2-28.9$ & $20.0-28.9$ & \\
$\quad$ Mean \pm SD & $24.2 \pm 2.7$ & $24.0 \pm 2.7$ & \\
Duration (months) & & & \\
Range & $3-15$ & & \\
Mean \pm SD & $8.5 \pm 4.0$ & & \\
Tinel's test +ve & $35(70.0 \%)$ & & \\
Phalen's test +ve & $39(78 \%)$ & & \\
\hline
\end{tabular}

females and 5 males). Most of the volunteers $(n=49)$ were also right-handed. In the control group, the dominant hand was examined in each subject. No statistical significance was found regarding the age, sex, and BMI between the ICTS group and the control group (Table 1).

\section{US findings}

Compared to the control group, the ICTS group had significantly higher m-CSA $(p<0.001)$, higher $\mathrm{m}$-CSA:u-CSA ratio $(p<0.001)$, higher $\mathrm{m}$-SR $(p=0.012)$, and higher palmar bowing $(p<0.001)$; meanwhile, the differences regarding the $\mathrm{u}$-CSA and the flattening ratio were insignificant between ICTS patients and controls (Table 2)

\section{Diagnostic utility of the $\mathrm{m}$-CSA and $\mathrm{m}$-CSA:u-CSA ratio} ROC curves were drawn to determine the diagnostic utility of the m-CSA and m-CSA:u-CSA ratio for the identification of patients with CTS. The areas under the curve (AUC) of the m-CSA and the m-CSA:u-CSA ratio were 0.792 (95\% CI $0.716-0.868)$ and 0.897 (95\% CI $0.862-0.939$ ) respectively (Figs. 1 and 2).

According to the data generated by the ROC curve, $11.78 \mathrm{~mm} 2$ was selected for the cut-off point of the $\mathrm{m}$ CSA while 2.97 was selected for the cut-off point of the m-CSA:u-CSA ratio. The sensitivity, specificity, and positive and negative predictive values for each of these cut-offs are shown in Table 3.

\section{Correlation between US findings and the median nerve EDX parameters}

M-CSA is significantly correlated with median nerve distal motor latency $(p=0.041)$, CMAP $(p=0.044)$, sensory 
Table 2 Comparison of the US findings between the ICTS group and the control group

\begin{tabular}{|c|c|c|c|c|c|}
\hline & ICTS group & Control group & Mean difference & $95 \% \mathrm{Cl}$ of the difference & $p$ \\
\hline \multicolumn{6}{|l|}{$\overline{m-C S A}\left(m^{2}\right)$} \\
\hline Range & $7-20$ & $6-12$ & & & \\
\hline Mean \pm SD & $14.6 \pm 3.7$ & $8.7 \pm 1.6$ & 5.92 & $4.79-7.05$ & $<0.001$ \\
\hline \multicolumn{6}{|l|}{$\mathrm{u}-\mathrm{CSA}\left(\mathrm{mm}^{2}\right)$} \\
\hline Range & $3-6$ & $3-6$ & & & \\
\hline Mean \pm SD & $3.96 \pm 1.1$ & $3.78 \pm 0.99$ & 0.18 & $0.24-0.59$ & 0.394 \\
\hline \multicolumn{6}{|c|}{ m-CSA:u-CSA ratio } \\
\hline Range & $2.00-5.33$ & $1.11-3.33$ & & & \\
\hline Mean \pm SD & $3.76 \pm 0.79$ & $2.36 \pm 0.45$ & 1.39 & $1.14-1.65$ & $<0.001$ \\
\hline \multicolumn{6}{|l|}{$\mathrm{m}-\mathrm{SR}$} \\
\hline Range & $0.5-1.6$ & $0.4-1.4$ & & & \\
\hline Mean \pm SD & $1.06 \pm 0.4$ & $0.87 \pm 0.3$ & 0.18 & $0.04-0.33$ & 0.012 \\
\hline \multicolumn{6}{|c|}{ Palmar bowing (mm) } \\
\hline Range & $0.9-2.1$ & $0.8-1.9$ & & & \\
\hline Mean \pm SD & $1.68 \pm 0.4$ & $1.15 \pm 0.3$ & 0.53 & $0.40-0.67$ & $<0.001$ \\
\hline \multicolumn{6}{|l|}{ Flattening ratio } \\
\hline Range & $1.3-4.0$ & $1.3-4.0$ & & & \\
\hline Mean \pm SD & $2.57 \pm 0.9$ & $2.61 \pm 0.8$ & 0.04 & $-0.38-0.29$ & 0.805 \\
\hline
\end{tabular}

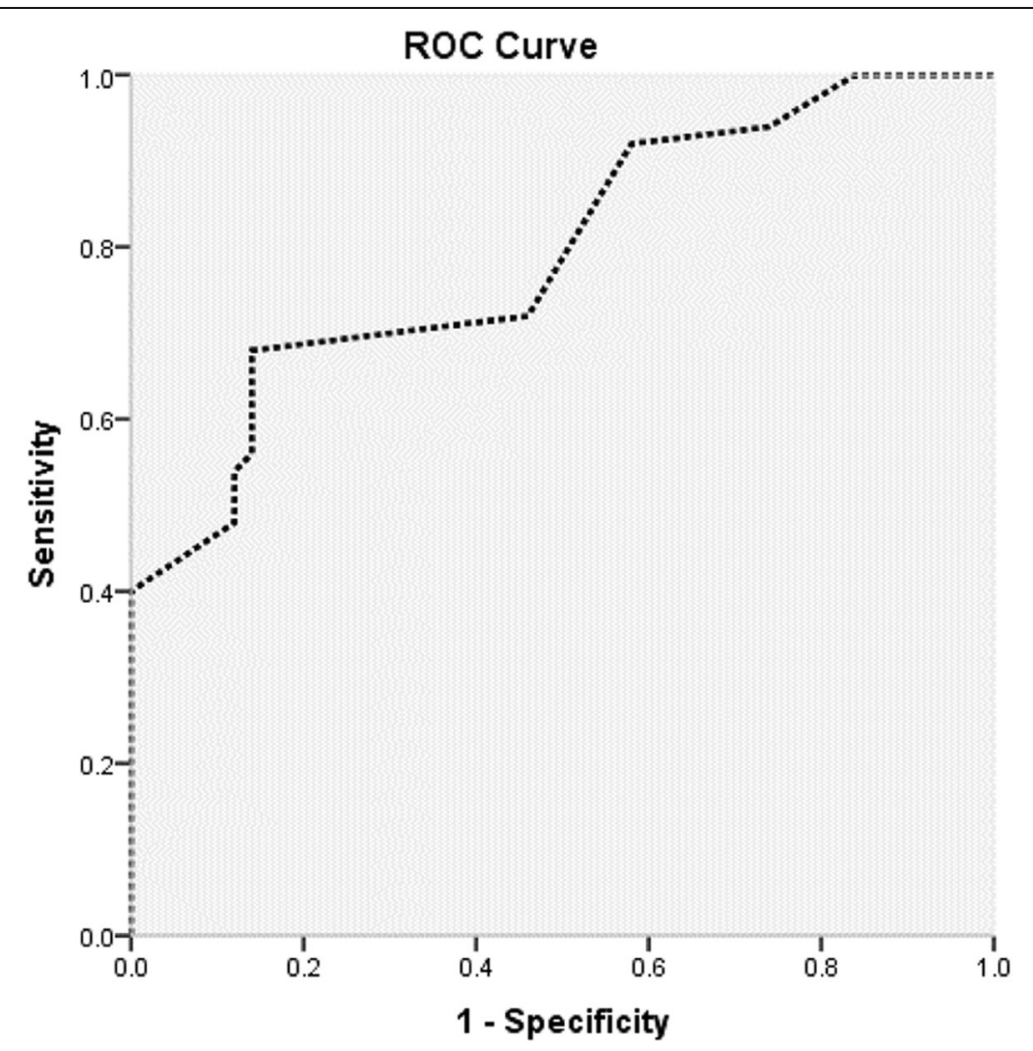

Fig. 1 ROC curve analysis of the ability of the m-CSA in the diagnosis of CTS at the cut-off point of $11.78 \mathrm{~mm}^{2}$ (AUC $=0.792$ ) 


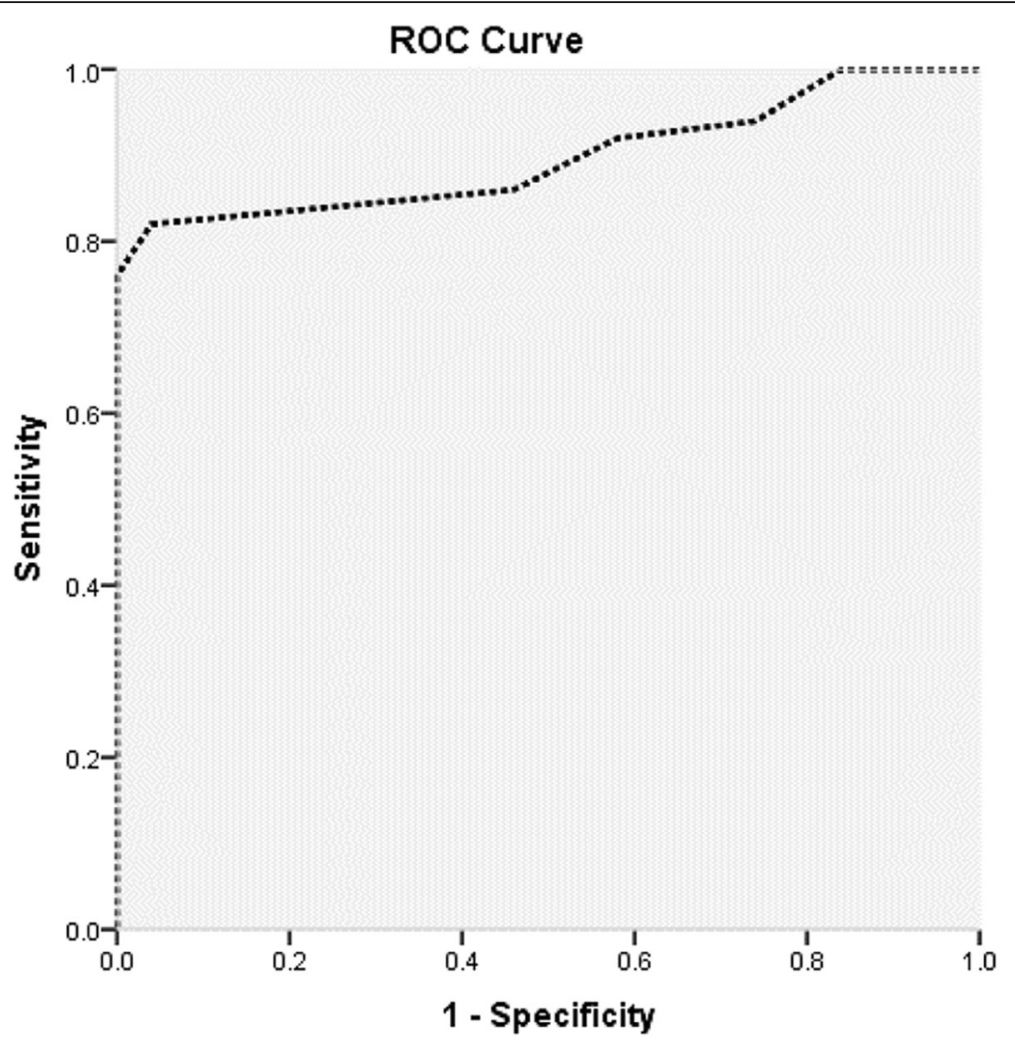

Fig. 2 ROC curve analysis of the ability of the m-CSA:u-CSA ratio in the diagnosis of CTS at the cut-off point of 2.97 (AUC = 0.897)

latency $(p=0.023)$, and sensory amplitude $(p=0.033)$. Similarly the m-CSA:u-CSA ratio is significantly correlated with median nerve distal motor latency $(p=0.026)$, CMAP $(p=0.027)$, sensory latency $(p=0.008)$, and sensory amplitude $(p=0.012)$ (Table 4$)$.

\section{Discussion}

The main findings of the present study were (a) ICTS group had significantly higher m-CSA, m-CSA:u-CSA ratio, m-SR, and palmar bowing than controls; (b) m-CSA: $\mathrm{u}$-CSA ratio at the cut-off point of 2.97 can diagnose CTS with sensitivity and specificity of 0.840 and 0.880 respectively while $\mathrm{m}$-CSA $\mathrm{mm}^{2}$ can diagnose CTS with sensitivity and specificity of 0.780 and 0.820 respectively.
In the present study, ICTS patients had a significantly higher m-CSA pisiform than the controls, which is in agreement with the findings reported by previous studies $[6,17,18]$. Similarly, the CTS patients in this study had a significantly higher m-CSA:u-CSA ratio than controls. This finding is consistent with the findings of several previous studies $[18,19]$.

Previous studies that assessed the ability of the m-CSA for the diagnosis of CTS have emerged conflicting results regarding the proper cut-off point or the diagnostic utility of this procedure. The m-CSA cut-off value varied from 9 to $15 \mathrm{~mm}^{2}$, the sensitivity of US m-CSA measurements differed between 62 and 97\% while specificity varied between 57 and 100\% for the diagnosis of CTS among other studies [20-24]. Inconsistencies between studies can be

Table 3 The diagnostic values of the m-CSA and m-CSA:u-CSA ratio for diagnosis of CTS

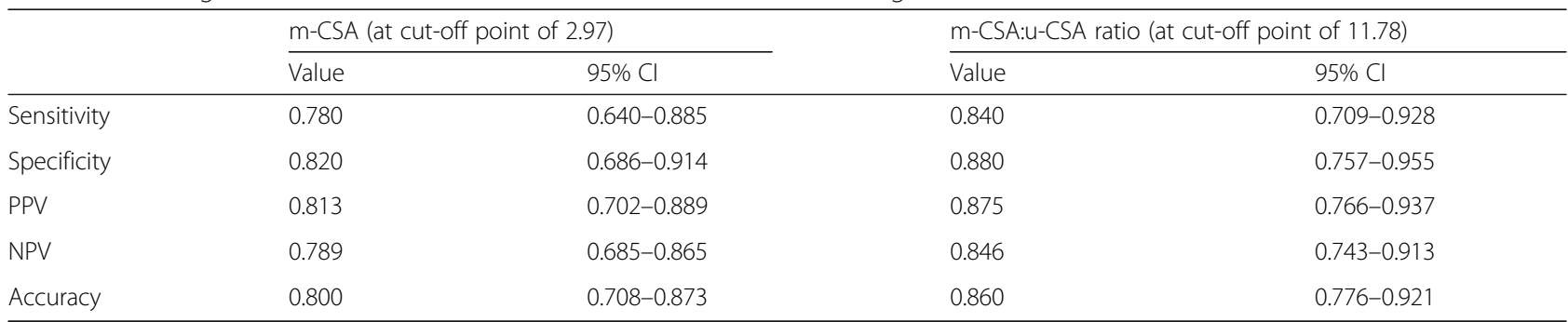

PPV positive predictive value, NPV negative predictive value 
Table 4 Correlation between the m-CSA and m-CSA:u-CSA ratio with the median nerve EDX parameters

\begin{tabular}{llllll}
\hline & \multicolumn{2}{l}{$\mathrm{m}-\mathrm{CSA}$} & & \multicolumn{2}{c}{ m-CSA:u-CSA ratio } \\
\cline { 2 - 3 } & $r$ & $p$ & & $r$ & $p$ \\
\hline Distal motor latency & 0.290 & $0.041^{*}$ & & 0.315 & $0.026^{*}$ \\
CMAP amplitude & 0.287 & $0.044^{*}$ & & 0.313 & $0.027^{*}$ \\
Sensory latency & 0.321 & $0.023^{*}$ & & 0.369 & $0.008^{*}$ \\
Sensory amplitude & 0.302 & $0.033^{*}$ & & 0.352 & $0.012^{*}$ \\
\hline
\end{tabular}

*Significant

attributed to the differences in selection criteria of patients and controls, the methods used in the diagnosis of CTS, and levels of the measured m-CSA.

In the present study, using the cut-off point of 11.78 $\mathrm{mm}^{2}$, the m-CSA showed sensitivity and specificity of 0.780 and 0.820 respectively at the level of pisiform bone in the diagnosis of CTS. In agreement with our findings, Atan and Günendi reported that $\mathrm{m}$-CSA at the cut-off point 11.95 $\mathrm{mm}^{2}$ had a sensitivity of 0.80 and a specificity of 0.80 at level of pisiform bone in the diagnosis of CTS [25]. However, the m-CSA varies depending on the person's biometric characteristics. US $\mathrm{m}$-CSA measurement was found to be increased with increasing age and with increasing BMI, and it is greater in males [26-28]. Accordingly, the specificity of US m-CSA measurement decreases. These facts prompted the measurement of the $\mathrm{u}-\mathrm{CSA}$ at the same level of $\mathrm{m}$-CSA measurement to calculate $\mathrm{m}$-CSA:u-CSA ratio in order to improve diagnostic accuracy for CTS.

Yurdakul et al. assessed the utility of the m-SR, palmar bowing, and m-CSA at the level of the pisiform bone and calculated the m-CSA:u-CSA ratio for the diagnosis of CTS. They reported that all of the US measurements were significantly higher in CTS patients than in the control group. These findings are in consistency of our findings [18].

However, Yurdakul et al. stated that the SR and palmar bowing are useful when there was a motor affection in the later stages of CTS [18]. In support to these observations, Buchberger et al. reported that SR, palmar bowing, and flattening ratio measurements are reliable for the diagnosis of CTS in late stages [16]. Also, Mohamed et al. found that ultrasonographic measurements of CSA at the inlet and flexor retinaculum have a relatively higher diagnostic accuracy than FR for CTS [29].

As shown in the results of the present study, the mCSA:u-CSA ratio had superiority, albeit modest, diagnostic accuracy for CTS over the m-CSA when measured at the same level. Using the cut-off point of 2.97, the m-CSA:u-CSA ratio showed a sensitivity and specificity of 0.840 and 0.880 respectively at the level of pisiform bone in the diagnosis of CTS. Consistent with the findings of this study, Atan and Günendi reported that m-CSA:u-CSA ratio at a cut-off point of 2.95 had a sensitivity of 0.86 and a specificity of 0.72 at the level of pisiform bone in the diagnosis of CTS [25].

In agreement with the results of the present study, Jiwa et al. investigated the use of a sonographic m-CSA: $\mathrm{u}-\mathrm{CSA}$ ratio in the diagnosis of CTS and reported that a cut-point of $>2.09$ yielded a sensitivity and specificity of $86 \%$ and $84 \%$ respectively [19].

The study by Yurdakul et al. found that the m-CSA:uCSA ratio at the cut-off point of $\geq 1.79$ is $70 \%$ sensitive

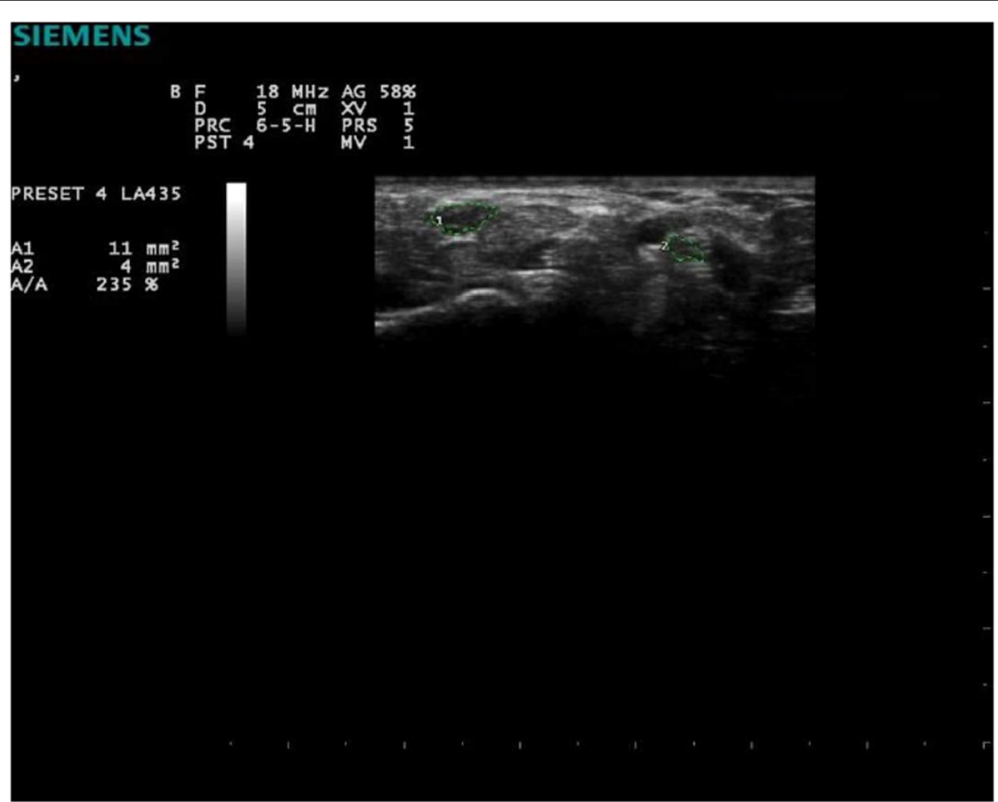

Fig. 3 With the palm facing upward, MSUS shows the proximal carpal tunnel and Guyon's canal in cross-section with median nerve located superficially over the flexor tendons and ulnar nerve and artery in the Guyon's canal 
and $76 \%$ specific in the diagnosis of CTS [18]. However, they did not compare this measurement with m-CSA measurement. In our results, we found higher sensitivity and specificity for the m-CSA:u-CSA ratio in the diagnosis of CTS. This can be related to the difference in the level of assessment of the ulnar nerve as in the study of Yurdakul et al. where the ulnar nerve was assessed at the Guyon's canal (Fig. 3 )[18].

The results of the present study showed that m-CSA and m-CSA:u-CSA ratio were significantly correlated with median nerve distal motor latency, CMAP, sensory latency, and sensory amplitude, albeit that m-CSA:uCSA ratio had stronger correlation than m-CSA with all median nerve EDX parameters. In agreement with our results, Kwon et al. found that median nerve CSA at inlet was significantly correlated with the median nerve motor and sensory latencies as well as with motor and sensory response amplitudes [30]. Also, in agreement with the findings of the present study, Yurdakul et al. found a statistically significant correlation between median nerve motor and sensory nerve action potential latencies and amplitudes. Lee et al. studied the correlation between CSA measurements made from the pisiform bone and EDX values and found that proximal swelling of the median nerve at the entrance to the carpal tunnel was correlated with median nerve conduction parameters [31]. Eom et al. measured the median-to-ulnar CSA ratio at the wrist in patients with CTS and found a significant correlation with electrophysiology findings [32]. These findings confirm the utility of the m-CSA:u-CSA ration in the diagnosis of CTS.

Certain limitations should be considered when interpreting the results of this study. We did not investigate the association between the US parameters and the severity of CTS symptoms, and we could not evaluate if the m-CSA:u-CSA ratio was useful to discriminate different severities of CTS. However, the aim of the study focused on the ability of US in diagnosis of the CTS.

\section{Conclusion}

Diagnosis of CTS can be established on the basis of measurement of m-CSA at level of pisiform bone and $\mathrm{m}$-CSA:u-CSA ratio. The m-CSA:u-CSA ratio is slightly superior to the m-CSA in diagnosis of CTS in terms of sensitivity and specificity.

The results of ratio measurement should be interpreted in conjunction with EDX studies as the presence of bifid median nerve may give false-positive ratio increment; on the other side, concomitant entrapment of the ulnar nerve at the Guyon's canal could affect diameter measurement of either nerves and is likely to cause false-negative ratio decrement.

\begin{abstract}
Abbreviations
US: Ultrasonography; CTS: Carpal tunnel syndrome; ICTS: Idiopathic carpal tunnel syndrome; M-CSA: Median nerve cross-sectional area; U-CSA: Ulnar nerve cross-sectional area; SUA: Serum uric acid; ESR: Erythrocyte sedimentation rate; CRP: C-reactive protein; RF: Rheumatoid factor; BMI: Body mass index; EDX: Electro-diagnostic testing; AUC: The areas under the curve; CMAP: Compound muscle action potential; ROC curve: Receiver operating characteristic curve
\end{abstract}

\section{Acknowledgements \\ Not applicable}

\section{Authors' contributions}

AS analyzed and interpreted the patients' data and contributed in performing statistical analysis of the results and major contribution in writing the manuscript. MK contributed to the analyzing and interpretation of patients' data and performing statistical analysis. AE was responsible for performing all electrodiagnostic studies present in the study. OG contributed to writing the manuscript. All authors read and approved the final manuscript.

\section{Funding \\ No funding}

\section{Availability of data and materials}

The datasets used and/or analyzed during the current study are available from the corresponding author on reasonable request

\section{Ethics approval and consent to participate}

The research was approved by the Institutional Research Board (IRB) of Mansoura University with code number: R.18.03.86 by date: March 13, 2018, and the written consent was obtained from all participants and approved by IRB.

Consent for publication

Not applicable in this study as there are no personal details.

\section{Competing interests}

The authors declare that they have no competing interests.

\section{Author details}

${ }^{1}$ Faculty of Medicine, Mansoura University, Mansoura, Egypt. ${ }^{2}$ Physical Medicine, Rheumatology and Rehabilitation Department, Faculty of Medicine, Mansoura University, Mansoura, Egypt.

Received: 6 July 2020 Accepted: 20 July 2020

Published online: 10 August 2020

\section{References}

1. Atroshi I, Gummesson C, Johnsson R, Ornstein E, Ranstam J, Rosen I (1999) Prevalence of carpal tunnel syndrome in a general population. JAMA. 282(2): 153-158

2. MacDermid JC, Doherty $T$ (2004 Oct) Clinical and electro diagnostic testing of carpal tunnel syndrome: a narrative review. J Orthop Sports Phys Ther. 34(10):565-588

3. Werner RA, Andary M (2011 Oct) Electrodiagnostic evaluation of carpal tunnel syndrome. Muscle Nerve. 44(4):597-607

4. Keith MW, Masear V, Chung KC, Maupin K, Andary M, Amadio PC et al (2009) American Academy of Orthopaedic Surgeons Clinical Practice Guideline on diagnosis of carpal tunnel syndrome. J Bone Joint Surg Am. 91: 2478-2479

5. Mhoon JT, Juel VC, Hobson-Webb LD (2012 Dec) Median nerve ultrasound as a screening tool in carpal tunnel syndrome: correlation of cross-sectional area measures with electrodiagnostic abnormality. Muscle Nerve. 46(6):871884

6. Kuo TT, Lee MR, Liao YY, Chen JP, Hsu YW, Yeh CK (2016 Jan 14) Assessment of median nerve mobility by ultrasound dynamic imaging for diagnosing carpal tunnel syndrome. PLoS One. 11(1):e0147051

7. Visser LH, Smidt MH, Lee ML (2008) High resolution sonography versus EMG in the diagnosis of carpal tunnel syndrome. J Neurol Neurosurg Psychiatry. 79:63-67 
8. Fu T, Cao M, Liu F, Zhu J, Ye D, Feng X, Xu Y, Wang G, Bai Y (2015 Jan 24) Carpal tunnel syndrome assessment with ultrasonography: value of inlet-tooutlet median nerve area ratio in patients versus healthy volunteers. PLoS One. 10(1):e0116777

9. Wong SM, Grifth JF, Hui AC, Tang A, Wong KS (2002) Discriminatory sonographic criteria for the diagnosis of carpal tunnel syndrome. Arthritis Rheum. 46:1914-1921

10. Beekman R, Visser LH (2003) Sonography in the diagnosis of carpal tunnel syndrome: a critical review of the literature. Muscle Nerve. 27:26-33

11. Ozben S, Acar H, Gunaydin S, Genc F, Ozer F, Ozben H (2012 Jun) The second lumbrical-interosseous latency comparison in carpal tunnel syndrome. J Clin Neurophysiol. 29(3):263-267

12. Basiri K, Katirji B (2015 Feb 17) Practical approach to electrodiagnosis of the carpal tunnel syndrome: a review. Adv Biomed Res. 4:50

13. Hobson-Webb LD, Massey JM, Juel VC, Sanders DB (2008) The ultrasonographic wrist-to-forearm median nerve area ratio in carpal tunne syndrome. Clin Neurophysiol. 119:1353-1357

14. Jablecki CK, Andary MT, Floeter MK, Miller RG, Quartly CA, Vennix MJ et al (2002) Practice parameter: electrodiagnostic studies in carpal tunnel syndrome: report of the American Association of Electrodiagnostic Medicine, American Academy of Neurology, and the American Academy of Physical Medicine and Rehabilitation. Neurology. 58:1589-1592

15. Buchberger W, Schön G, Strasser K, Jungwirth W (1991) High-resolution ultrasonography of the carpal tunnel. J Ultrasound Med. 10:531-537

16. Buchberger W, Judmaier W, Birbamer G, Lener M, Schmidauer C (1992) Carpal tunnel syndrome: diagnosis with high-resolution sonography. AJR Am J Roentgenol. 159:793-798

17. Ulaşli AM, Duymuş M, Nacir B, Rana Erdem H, Koşar U (2013) Reasons for using swelling ratio in sonographic diagnosis of carpal tunnel syndrome and a reliable method for its calculation. Muscle Nerve. 47:396-402

18. Yurdakul OV, Mesci N, Çetinkaya Y, Geler KD (2016) Diagnostic significance of ultrasonographic measurements and median-ulnar ratio in carpal tunnel syndrome: correlation with nerve conduction studies. J Clin Neurol. 12:289294

19. Jiwa N, Abraham A, Bril V, Katzberg HD, Lovblom LE, Barnett C, Breiner A (2018 Nov) The median to ulnar cross-sectional surface area ratio in carpal tunnel syndrome. Clin Neurophysiol. 129(11):2239-2244

20. Wiesler ER, Chloros GD, Cartwright MS, Smith BP, Rushing J, Walker FO (2006) The use of diagnostic ultrasound in carpal tunnel syndrome. J Hand Surg Am. 31:726-732

21. McDonagh C, Alexander M, Kane D (2015) The role of ultrasound in the diagnosis and management of carpal tunnel syndrome: a new paradigm. Rheumatology (Oxford). 54:9-19

22. Tagliafco A, Bignotti B (2015) New parameters for evaluating peripheral nerve disorders on sonography and magnetic resonance imaging. $J$ Ultrasound Med. 34:1523

23. Padua L, Coraci D, Erra C, Pazzaglia C, Paolasso I, Loreti C, Caliandro P, Hobson-Webb LD (2016) Carpal tunnel syndrome: clinical features, diagnosis, and management. Lancet Neurol. 15:1273-1284

24. Tagliafico AS (2016) Peripheral nerve imaging: not only cross- sectional area. World J Radiol. 8:726-728

25. Atan T, Günendi Z (2018 Feb 23) Diagnostic utility of the sonographic median to ulnar nerve cross-sectional area ratio in carpal tunnel syndrome. Turk J Med Sci. 48(1):110-116

26. Won SJ, Kim BJ, Park KS, Yoon JS, Choi H (2013) Reference values for nerve ultrasonography in the upper extremity. Muscle Nerve. 47:864-871

27. Bathala L, Kumar P, Kumar K, Shaik A, Visser LH (2014) Normal values of median nerve cross-sectional area obtained by ultrasound along its course in the arm with electro-physiological correlations, in 100 Asian subjects. Muscle Nerve. 49:284-286

28. Qrimli M, Ebadi $H$, Breiner A, Siddiqui H, Alabdali M, Abraham A, Lovblom LE, Perkins BA, Bril V (2016) Reference values for ultrasonography of peripheral nerves. Muscle Nerve. 53:538-544

29. Mohamed Fl, Kamel SR, Hafez AE (2018) Usefulness of neuromuscular ultrasound in the diagnosis of idiopathic carpal tunnel syndrome. Egypt Rheumatol Rehabil 45:65-73

30. Kwon HK, Kang HJ, Byun CW, Yoon JS, Kang CH, Pyun SB (2014) Correlation between ultrasonography findings and electrodiagnostic severity in carpal tunnel syndrome: 3D ultrasonography. J Clin Neurol. 10(4):348-353
31. Lee CH, Kim TK, Yoon ES, Dhong ES (2005) Correlation of high-resolution ultrasonographic findings with the clinical symptoms and electrodiagnostic data in carpal tunnel syndrome. Ann Plast Surg. 54:20-23

32. Eom Yl, Choi MH, Kim YK, Joo IS (2015) Sonographic findings in the ulnar nerve according to the electrophysiologic stage of carpal tunnel syndrome. J Ultrasound Med. 34:1027-1034

\section{Publisher's Note}

Springer Nature remains neutral with regard to jurisdictional claims in published maps and institutional affiliations.

\section{Submit your manuscript to a SpringerOpen ${ }^{\circ}$ journal and benefit from:}

- Convenient online submission

- Rigorous peer review

- Open access: articles freely available online

- High visibility within the field

- Retaining the copyright to your article

Submit your next manuscript at $\boldsymbol{\nabla}$ springeropen.com 